\title{
THE RELATIONSHIP BETWEEN CO2 EMISSIONS AND GROSS CAPITAL FORMATION IN TURKEY AND KUWAIT
}

Elma Satrovic, Adnan Muslija, Sadeq J. Abul

\section{Abstract}

The aim of this paper is to explore the potential link between gross capital formation and CO2 emissions by using the Toda and Yamamoto approach. The annual time-series data were collected for the period 19712014. Due to the fact that Kuwait aims to become a major trading hub by 2035, it has made significant efforts to improve the infrastructure. Moreover, Turkey is also making strong efforts to improve the manufacturing sector as well as infrastructure, and represents an important trading hub that links Europe with the Middle East. Thus, Turkey and Kuwait are expected to strengthen their economic ties and expand trade, which was the motivation for comparing the link of interest in these two countries. The study's findings confirm the bidirectional links between all of the variables of interest not only in the case of Turkey but also in the case of Kuwait, suggesting some important policy implications.

Keywords: CO2 emissions, energy, gross capital formation, Toda and Yamamoto approach

JEL classification: $044, E 22, Q 43, Q 56$

\section{INTRODUCTION}

Sustainable economic development and the degradation of the environment are considered to be two of the most challenging issues facing humanity (Aye and Edoja 2017). The degradation of the environment is strongly determined by population growth and consistent economic growth based on technology that consumes significant amounts of fossil-fuelbased energy (Huesemann and Huesemann 2008). Cherniwchan (2012) indicates that economic growth is driven by industrialization. However, industrialization plays a key role in the degradation process. Lu (2017) suggests that economic growth is also strongly driven by the availability of inputs; thereby, the over-exploitation of natural resources, the destruction of wildlife and changes in the climate connected with industrialization will lead to serious environmental issues. This is why many governments are in a dilemma over whether to continue using fossil-fuel-based energy or
Elma Satrovic, $\mathrm{PhD}$ (corresponding author) Associate Professor, University of Novi Pazar, Serbia Assistant Professor, Çağ University

Email: elmasatrovic@cag.edu.tr Address: Yaşar Bayboğan Kampüsü Adana-Mersin Karayolu üzeri 33800 Mersin Turkey

Adnan Muslija, $\mathrm{PhD}$ Independent Researcher Email: adnanmuslija@msn.com Bosnia and Herzegovina

Sadeq J. Abul, PhD Independent Economic Advisor Email: sadeqabul@gmail.com Kuwait 
to tie economic growth to clean energy. This dilemma is complex, taking into account the fact that Dollar, Kleineberg, and Kraay (2016) indicated that growth based on fossil fuels may increase the standard of living, whereas Di Fonzo et al. (2013) suggested that living conditions may be harmed by the greenhouse gases emissions connected with fossils. Thus, it is of key importance to consider alternative sources of energy.

The degradation of the environment receives special attention among the research community nowadays. As indicated above, greenhouse gases (especially $\mathrm{CO} 2$ emissions) tend to play a significant role in climate change and global warming. The British petroleum energy statistical review suggests that carbon dioxide emissions in OECD countries have increased by $0.7 \%$ in the last observed year (2017) compared to 2016, whereas the record flume of CO2 (at the global level) was emitted by non-OECD countries $(62.8 \%$ of total $\mathrm{CO} 2$ emissions). Thereby, developing countries have recorded a rise in $\mathrm{CO} 2$ emissions. For instance, India recorded a growth rate of $4.4 \%$ in 2017 compared to 2016. Significant growth of $12.7 \%$ has also been recorded in the case of Turkey. Moreover, Figure 1 suggests the rising trend in $\mathrm{CO} 2$ emissions in Turkey during the period of interest, which was the motivation for analyzing the link of interest for this country.

These statistics have placed Turkey among the top $15 \mathrm{CO} 2$ emissions countries in the world. Rahman and Ahmad (2019) state that the consumption of oil, coal and energy were among the most significant generators of CO2 emissions. Alam et al. (2016), moreover,

Figure 1. $\mathrm{CO} 2$ emissions

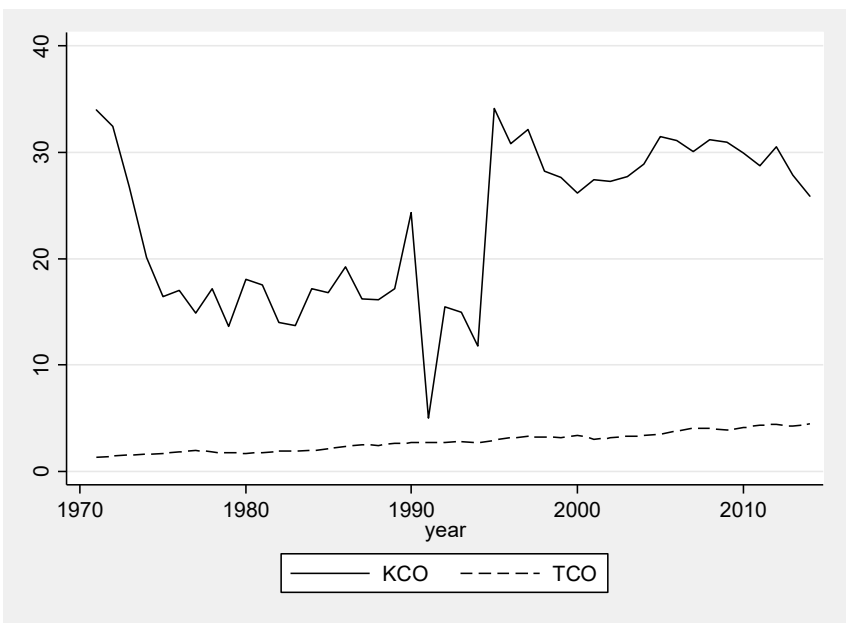

Note: $\mathrm{KCO}$ - CO2 emissions in Kuwait; TCO - CO2 emissions in Turkey

Source: Computed by the Authors place energy as the top generator of carbon dioxide emissions. The use of energy in Turkey is mainly based on oil, coal and natural gas consumption, respectively, in 2017. The population growth in Turkey has resulted in an increasing energy demand over the period of interest (Figure 2). Thus, Turkey is recognized as the fastest growing country in terms of electricity demand among the OECD economies (http://www.mfa.gov. tr/turkeys-energy-strategy.en.mfa). In addition to the significant increase in energy demand, a very important characteristic of the Turkish energy market is its strong dependence on imports. Thus, Turkey still lags behind in terms of energy production. This is especially true for renewable energy. As indicated above, the main source of energy is oil in Turkey, followed by coal, which is cheap but tends seriously to damage the environment.

In addition to energy consumption based on coal and oil, it is important to recognize the other factors leading to environmental depletion in Turkey. The most serious factors include gross capital formation (GCF) and FDI. This is especially true in the case of developing countries. However, the findings to date on this issue have not been explored very intensively in either country of interest, which was the motivation for conducting this study. The link between gross capital formation and carbon dioxide emissions should be analyzed while taking into account the level of development. For instance, developing countries in general make investments to develop the infrastructure and production technology whereas developed countries invest in software and information technology.

Figure 2. Energy consumption

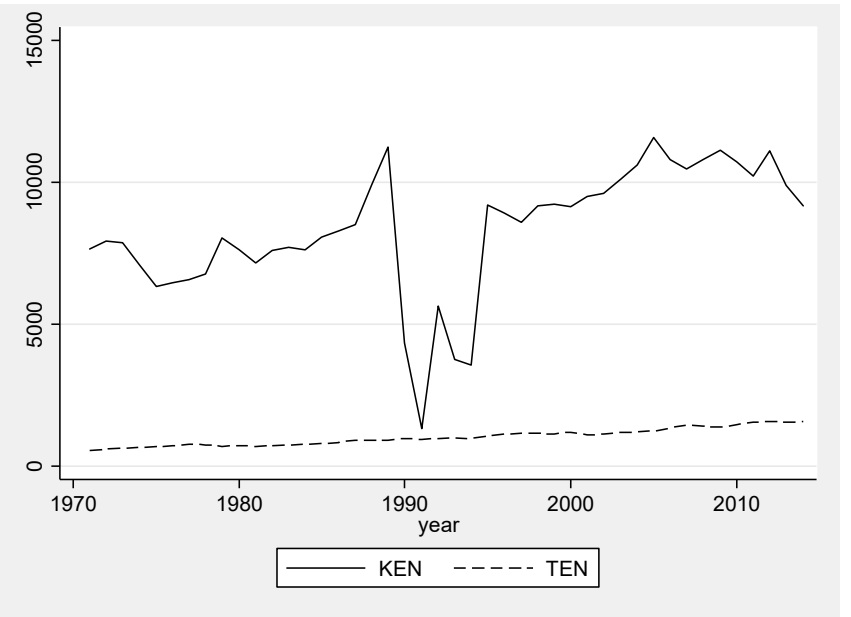

Note: KEN - Energy consumption in Kuwait; TEN - Energy consumption in Turkey

Source: Computed by the Authors 
Bukhari, Shahzadi and Shakil Ahmad (2014) and Ahmad et al. (2019) suggested that investment tends to harm the environment of developing countries, since carbon dioxide emissions increase in the earlier stage of growth and tend to decrease a rise in income and the stabilization of the growth process. In fact, $\mathrm{CO} 2$ emissions are the result of a rise in energy consumption based on fossil fuels. The firms that are recognized as $\mathrm{CO} 2$ gluttons tend to place their production in less developed economies since these countries have, in general, weaker environmental laws compared to developing ones. Gokmenoglu and Taspinar (2016) suggest that the production costs may be significantly reduced in this manner. Gross capital formation has recorded an increasing trend in both countries during the period of interest (Figure 3 ).

Figure 3. Gross capital formation

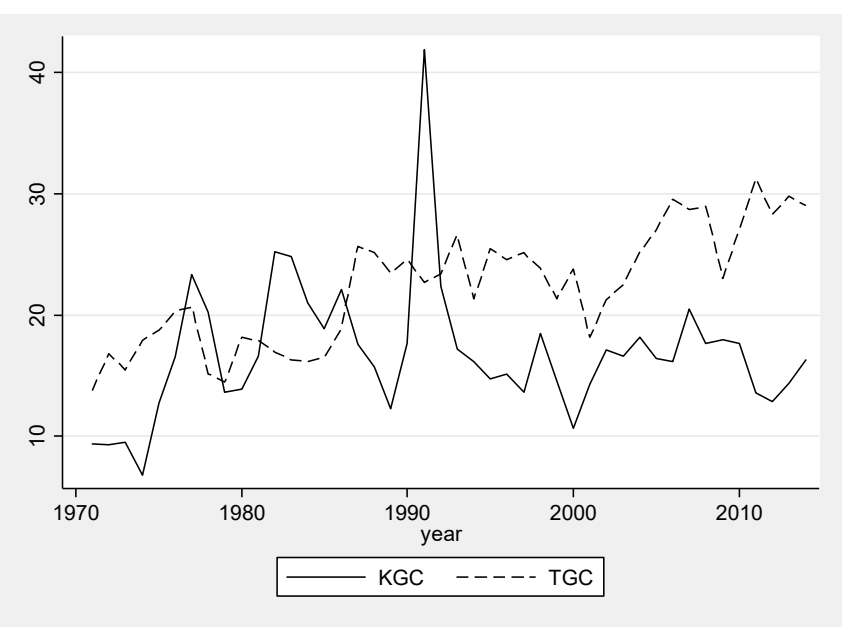

Note: KGC - Gross capital formation in Kuwait; TGC - Gross capital formation in Turkey

Source: Computed by the Authors

Kuwait is a small country situated in the northwest of the Arabian Gulf. Throughout the last few centuries, Kuwait has been a mid-point in the Gulf trading patterns between the Iraqi ports and the Gulf coast for money and other goods. Prior to the discovery of oil, its major economic activities were pearling, fishing, boat-building, small-scale trading and merchant shipping. Kuwait was active during the early centuries along the old Silk Road between China and other Middle Eastern countries. The Silk Road stretched from East to West and served to transport several types of goods, such as silk, spices and jewels as well as coins, in the distant past. Compared with 1946, when the first exports of oil were recorded, Kuwait now enjoys one of the highest per capita incomes of all countries, and the per capita share of gross national product (GNP) in 2018 amounted to USD 73017. The non-Kuwaiti population represents about $70 \%$ of the total population, while Kuwaiti citizens constitute approximately $30 \%$ only. Both the Kuwaiti and non-Kuwaiti populations have grown at a high rate during the past three decades. This high growth caused an increase in demand for education, electricity, water, transportation and health, which naturally resulted in increased energy consumption (Figure 2) and led to increased $\mathrm{CO} 2$ emissions (Figure 1). In 2010, the Kuwaiti government developed a long-term plan to address the structural imbalances and diversify the economy. According to this plan (2010-2035), Kuwait would become a financial and trade center.

However, Turkey was also involved in the Silk Road through the Anatolian ports on the Black Sea which served, in the past, as a bridge between East and West by importing silk from the East and exporting it to the West. The Turkish economy has witnessed remarkable growth during the last few decades. In fact, Turkey enjoys an active trade relationship with Kuwait. Several projects have been implemented by Turkish companies in Kuwait, such as the airport, fuel stations and other mega projects. As mentioned earlier, the Kuwaiti economy is based on oil and Kuwait has taken steps to implement the long-term plan of 2035 that aims to diversify the economy. Meanwhile, Turkey has succeeded, during the last decade, in reforming its economy and also has a clear plan for economic growth in the future. Both countries have a clear strategy for the future with new infrastructure projects and participation in the new Silk Road, and also have the potential for more growth in their economy. The aim of this paper, by comparing Kuwait as an oil exporting country with Turkey as an oil importing country, is to contribute to the literature on the relationship between $\mathrm{CO} 2$ emissions, gross capital formation and energy consumption, taking into consideration each country's strategy of planned future growth, participating in trade and the Silk Road and implementing more infrastructure in both countries. From this comparison, it will be helpful to consider two cases: the first is that of an oil exporter while the second is that of an oil importer. The main issue here is whether or not the growth of the economy increases $\mathrm{CO} 2$ emissions.

Furthermore, the similar economic activity conducted in Kuwait and Turkey respectively makes it helpful to compare the findings on the relationship between $\mathrm{CO} 2$ emissions, gross capital formation and energy consumption in both economies that will play a significant role in the trade hub in the future. This will help researchers to devise policy recommendations 
to be implemented in both countries. The link between gross capital formation, $\mathrm{CO} 2$ emissions and energy consumption as the major source of $\mathrm{CO} 2$ emissions has been debated by many authors, especially in developing countries. However, so far, empirical evidence is lacking in the case of Turkey and Kuwait, which represents the research problem to be investigated in this paper. Thus, the first contribution of this paper to the literature lies in the fact that empirical evidence is provided on this issue as well as a comparative analysis of Turkey and Kuwait. Secondly, the Toda and Yamamoto approach was used, which makes it possible to control for the variables that may be integrated in a different order. Thirdly, these findings have been compared with other studies dealing with the link between gross capital formation and $\mathrm{CO} 2$ emissions. Finally, the latest available data have been used, which provide significant policy implications for decision makers by presenting the opportunities for collaboration between the countries of interest. Thus, after the introduction, the literature review shall be discussed. In addition, the data used together with the methodological overview shall be mentioned. The most important empirical findings are presented in the results section. The interpretation of the results leads to the concluding section, which summarizes the policy recommendations.

\section{LITERATURE REVIEW}

A tremendous number of studies have appeared on the relationship between $\mathrm{CO} 2$ emissions, gross capital formation and energy consumption in the literature during the last three decades. This vast amount of literature regarding the subject reflects the future of these nations and the health of their inhabitants. This number of published papers and articles in academic journals makes it impossible to discuss all their findings here. Therefore, only the most relevant recent papers will be discussed and reviewed hereby.

The relationship between $\mathrm{CO} 2$ emissions and economic growth has been tackled by using different analyses and research streams. Most of the statistical tools have been used to examine the relationship between $\mathrm{CO} 2$ emissions and economic growth, by adding more variables that might affect $\mathrm{CO} 2$ emissions, such as trade, energy consumption, urban population, gross fixed capital formation, production structure, per capita income, financial development, human factors and foreign direct investment inflows. Other research has focused on examining the relationship between $\mathrm{CO} 2$ emissions and economic growth by seeking evidence of this relationship with an inverted
U-shaped based on the theme of the Environmental Kuznets Curve (EKV) hypotheses, which were introduced by Kuznets in 1955. In the following, the most recent literature that is relevant to this study will be discussed and reviewed. In recent studies, Thaker et al. (2019), for example, revealed the positive impacts of electricity consumption on economic growth in Malaysia and found an indirect causality running from electricity consumption to economic growth only, while Abul, Satrovic and Muslija (2019) found that economic growth in the GCC countries has a positive impact on energy consumption and a negative relationship with $\mathrm{CO} 2$, and also that the joint influence of $\mathrm{CO} 2$ and electricity consumption on GDP is significant. Accordingly, they argue, GCC countries must consider the environmental problems associated with fossilfuel-based energy. Meanwhile, Bashir et al. (2019) examined the long-run causality relationship between economic growth and three variables, namely $\mathrm{CO} 2$ emissions, energy consumption and human capital, in Indonesia for the period 1985-2017. They revealed a short-run causality between $\mathrm{CO} 2$ emissions and energy consumption, whereas the three variables (human capital, consumption energy and economic growth) cause $\mathrm{CO} 2$ emissions in the short-run. Moreover, Islam, Cheng and Rajib (2012) revealed a significant relationship between trade and $\mathrm{CO} 2$ emissions from gas fuel in Bangladesh for the period 1976-2008. Bekun, Emir and Sarkodie (2019) conducted a similar study for South Africa for the period 1960-2016, using an integration approach, and found an equilibrium long-run relationship between energy consumption and GDP, taking into consideration three variables (labor, capital, and $\mathrm{CO} 2$ emissions). Their results show that the pattern of the long-term relationship is U-shaped, suggesting that the higher economic growth causes a lower increase in energy consumption.

On the other hand, while the relationship between $\mathrm{CO} 2$ emissions and economic growth in Kuwait has been tackled in the previous literature within the scope of GCC countries, to the researchers' knowledge, no study has investigated this subject with regard to Kuwait as a case study alone, which distinguishes this study from previous ones. The main studies regarding GCC countries were conducted by: Abul, Satrovic and Muslija (2019); Howarth et al. (2017); Asif, Sharma and Adow (2015); Osman, Gachino and Hoque (2016); Hamrita and Mekdam (2016); Magazzino (2016); Sweidan and Alwaked (2016); and Salahuddin, Gow and Ozturk (2015). However, Turkey's case has been investigated by more researchers, such as: Korhan and Sadeghieh (2019); Gokmenoglu and Taspinar (2016); Ozturk and Oz (2016); Yildirim and Sakarya (2016); Gokmenoglu, Ozataca and Eren (2015); Bozkurt and 
Akan (2104), Saatci and Durmul (2013) and Halicioglu (2009). The studies to date lack a comparative analysis between Turkey and Kuwait in terms of the linkage among $\mathrm{CO} 2$ emissions, gross capital formation and energy consumption. Herein, this study aims to fill this gap in the literature by providing empirical evidence on this issue using a longer time-series and applying the Toda and Yamamoto approach.

\section{DATA AND METHODOLOGY}

This section presents the time-series used in the research. The data have been collected at the annual level. In addition to a brief presentation of the data used, the methodology employed is also summarized in the following paragraphs.

\section{Data}

This paper investigates the potential causal trivariate relationship. Due to their strong historical and cultural links, the data for the cases of Turkey and Kuwait for the period 1971-2014 has been collected in order to make comparison. The source of the data is the World Bank. The first time-series of interest is carbon dioxide emissions. $\mathrm{CO}$ denotes $\mathrm{CO} 2$ emissions (metric tons per capita). The justification for employing this variable is provided by Akbulut Bekar (2018), Beser and Beser (2017), and Polat and Ergun (2018). With regards to the proxy of gross capital formation, Oyedokun (2019) states that GCF- gross capital formation (\% of GDP) - is an appropriate proxy, which is accepted in this paper as well. Taking into account the fact that fossil-fuel-based energy is one of the most important contributors to $\mathrm{CO} 2$ emissions, the researchers considered it necessary to include this macroeconomic term in the analysis of interest. Rahman and Ahmad (2019) include ENE - energy use (kg of oil equivalent per capita) - in their analysis which was considered sufficient justification to include this proxy of energy consumption.

\section{Methodology}

To analyze the trivariate link of interest, time-series econometrics was employed. Since the Toda and Yamamoto approach enables us to control for the variables that are integrated of a different order, it was used to provide empirical evidence on this issue. The first step in this analysis was to control for the presence of the unit root. Augmented Dickey-Fuller-ADF
(Satrovic 2019), Phillips-Perron-PP as well as Perron unit root break point tests were used in this paper to test for the stationarity of the variables. Under the null hypothesis, the variance is not constant over time, implying that the time-series are non-stationary. The formalization of the Augmented Dickey-Fuller test is given by Said and Dickey (1984) as (Eq. 1):

$y_{t}=\beta^{\prime} D_{t}+\varphi y_{t-1}+\sum_{j=1}^{p} \omega_{j} \Delta y_{t-j}+\varepsilon_{t}$

The meaning of the parameters can be summarized as follows: error terms that are not correlated are denoted by $\varepsilon_{t}$ : the vector representation of deterministic terms is given by $D_{t}$. In addition to the ADF test, this paper also uses the Phillips-Perron-PP test. To formalize this test (Eq. 2) the assumptions of Phillips and Perron (1988) are as follows:

$\Delta y_{t}=\beta^{\prime} D_{t}+\pi y_{t-1}+u_{t}$

In Eq. 2, the error terms $\left(u_{t}\right)$ may be heteroscedastic and $I(0)$. After testing for the stationary properties of the variables, one may proceed further to the estimation of the potential causal link between $\mathrm{CO} 2$ emissions, gross capital formation and energy consumption. Due to the fact that the focus of interest is to compare the case of two countries (Turkey and Kuwait), Equations 3 and 4 have been estimated. The formalization of these equations is given by (Toda and Yamamoto, 1995):

$$
\begin{aligned}
& y_{t}=\mu+\sum_{i=1}^{p+m} \alpha_{i} y_{t-i}+\sum_{i=1}^{p+m} \beta_{i} x_{t-i}+u_{1 t} \\
& x_{t}=\mu+\sum_{i=1}^{p+m} \gamma_{i} x_{t-i}+\sum_{i=1}^{p+m} \delta_{i} y_{t-i}+u_{2 t}
\end{aligned}
$$

The most important parameters to determine in Equations 3 and 4 are the optimal number of lags ( $p$ ) as well as the max order of integration $(m)$. As indicated above, error terms are denoted by $u_{t}$, lack autocorrelation, and are expected to be normally distributed. To determine the max order of integration, it is necessary to find the order of integration. Given that this order equals one, in that case, $m^{\prime}=1$. The optimal number of lags is determined by utilizing the straight forward procedure that follows up the information 
criteria. Finally, evidence of a causal link between the variables of interest will be provided by estimating Equations 5 and 6:

$$
\begin{aligned}
& y_{t}=\mu+\sum_{i=1}^{p \prime+m^{\prime}} \alpha_{i} y_{t-i}+\sum_{i=1}^{p /+m^{\prime}} \beta_{i} x_{t-i}+u_{1 t} \\
& x_{t}=\mu+\sum_{i=1}^{p^{\prime}+m^{\prime}} \gamma_{i} x_{t-i}+\sum_{i=1}^{p^{\prime}+m^{\prime}} \delta_{i} y_{t-i}+u_{2 t} .
\end{aligned}
$$

The null hypothesis of the Toda Yamamoto Granger causality test indicates no uni/bidirectional links between $\mathrm{CO} 2$ emissions, gross capital formation and energy consumption in the case of Turkey and Kuwait. Apart from these findings, the alternative implies the potential causal links between the variables of interest, which is in accordance with the economic theory and empirical evidence to date (Rahman and Ahmad 2019).

\section{EMPIRICAL RESULTS}

The most commonly used measures of descriptive statistics are utilized to describe the data used in this analysis (Table 1). With regards to the proxy of $\mathrm{CO} 2$ emissions, these $\mathrm{CO} 2$ emissions (metric tons per capita) are, on average, lower in Turkey compared to Kuwait. The maximum value of this variable for the case of Turkey is reported in the last observed year while the minimum value is reported in the first year of interest, recording an increasing trend. In terms of Kuwait, the maximum value is recorded for 1995 whereas the minimum value is recorded for 1991. While analyzing this variable, it is important to keep in mind the significant differences in the population density in these two countries.
Gross capital formation (\% GDP) recorded the minimum value in the case of Turkey in 1971 while the maximum value relates to 2011 . This indicates that a significant increase occurred in Turkey during the period of interest. Macroeconomic performance made significant improvements in Turkey after the 20082009 financial crises, which has positively influenced the inflow of investment. The maximum value of gross capital formation (\% GDP) for Kuwait is recorded for 1991, while the minimum is for 1974 , due to the oil crisis.

However, Turkey records a higher inflow of investment, on average, compared to Kuwait. Finally, energy use ( $\mathrm{kg}$ of oil equivalent per capita) reached a maximum value for the case of Turkey in 2012 whereas the minimum value was for 1971 . Kuwait reached the maximum value in 2005 and minimum in 1991.

Kuwait displays a significantly higher average value of energy use ( $\mathrm{kg}$ of oil equivalent per capita) compared to Turkey, which is expected, assuming that Kuwait is one of the most important exporters of oil in the world. As indicated in the methodological part, the next step is to examine the stationary properties of the variables. To ease the comparison and interpretability, the natural logarithms have been calculated. The log level values of $\mathrm{CO}$ and GCF were found to contain the unit root for both countries (at a 5\% significance level) while employing the Augmented DickeyFuller-ADF test (Table 2). However, ENE was not found to contain the unit root for Turkey at the $5 \%$ significance level. To provide more convincing evidence on the stationary properties, the stationary properties of the first difference were tested. The first difference of all of the time-series of interest was found to be stationary.

Considering the fact that the first differences were found to be stationary, the researchers aimed to provide more convincing evidence about the stationary properties of the variables. For this purpose, the Phillips-Perron-PP test (Table 3) was employed. The

Table 1. The description of the data

\begin{tabular}{|c|cccccc|}
\hline Variable & \multicolumn{3}{|c}{ CO } & \multicolumn{3}{c|}{ GCF } \\
\hline country & Turkey & Kuwait & Turkey & Kuwait & Turkey & Kuwait \\
mean & 2.80 & 24.00 & 22.29 & 16.85 & 1023.71 & 8203.28 \\
sd & 0.92 & 7.20 & 4.79 & 5.58 & 297.11 & 2455.05 \\
max & 4.49 & 34.04 & 31.27 & 41.86 & 1585.40 & 11544.20 \\
min & 1.34 & 5.01 & 13.73 & 6.78 & 547.13 & 1322.23 \\
skewness & 0.218 & -0.478 & -0.015 & 1.967 & 0.358 & -1.122 \\
kurtosis & 1.913 & 2.250 & 1.907 & 10.441 & 2.033 & 3.919 \\
\hline
\end{tabular}

Source: Computed by the Authors 
Table 2. Augmented Dickey-Fuller (ADF) test

\begin{tabular}{|c|c|c|}
\hline Country & Variable & Statistics \\
\hline Turkey & \multirow{2}{*}{$\ln C O$} & Mackinnon approximate $p$-value $Z(t)=0.1020$ \\
\hline Kuwait & & MacKinnon approximate $p$-value $Z(t)=0.0938$ \\
\hline Turkey & \multirow{2}{*}{ D.InCO } & MacKinnon approximate $p$-value $Z(t)=0.0000$ \\
\hline Kuwait & & MacKinnon approximate $p$-value $Z(t)=0.0002$ \\
\hline Turkey & \multirow{2}{*}{$\operatorname{lnGCF}$} & MacKinnon approximate $p$-value $Z(t)=0.0857$ \\
\hline Kuwait & & Mackinnon approximate $\mathrm{p}$-value $\mathrm{Z}(\mathrm{t})=0.0547$ \\
\hline Turkey & \multirow{2}{*}{ D.InGCF } & Mackinnon approximate $\mathrm{p}$-value $\mathrm{Z}(\mathrm{t})=0.0000$ \\
\hline Kuwait & & Mackinnon approximate $p$-value $Z(t)=0.0150$ \\
\hline Turkey & \multirow{2}{*}{ InENE } & MacKinnon approximate $p$-value $Z(t)=0.0285$ \\
\hline Kuwait & & Mackinnon approximate $\mathrm{p}$-value $\mathrm{Z}(\mathrm{t})=0.5410$ \\
\hline Turkey & \multirow{2}{*}{ D.InENE } & MacKinnon approximate $p$-value $Z(t)=0.0000$ \\
\hline Kuwait & & MacKinnon approximate $p$-value $Z(t)=0.0252$ \\
\hline
\end{tabular}

Source: Computed by the Authors

Table 3. Phillips-Perron test and Perron unit root breakpoint tests

\begin{tabular}{|c|c|c|c|}
\hline Country & Variable & Statistics (Phillips-Perron test) & $\begin{array}{l}\text { Statistics (Perron unit root } \\
\text { breakpoint test) /trend and } \\
\text { intercept included/ }\end{array}$ \\
\hline Turkey & \multirow{2}{*}{$\ln C O$} & MacKinnon approximate $p$-value $Z(t)=0.5963$ & t-Statistics $p$-value $=0.0680$ \\
\hline Kuwait & & MacKinnon approximate $\mathrm{p}$-value $\mathrm{Z}(\mathrm{t})=0.0032$ & $\mathrm{t}$-Statistics p-value $=0.0000$ \\
\hline Turkey & \multirow{2}{*}{ D.InCO } & MacKinnon approximate $\mathrm{p}$-value $\mathrm{Z}(\mathrm{t})=0.0000$ & t-Statistics $p$-value $=0.0000$ \\
\hline Kuwait & & MacKinnon approximate $p$-value $Z(t)=0.0000$ & t-Statistics $p$-value $=0.0000$ \\
\hline Turkey & \multirow{2}{*}{ InGCF } & MacKinnon approximate $p$-value $Z(t)=0.1662$ & t-Statistics $p$-value $=0.0872$ \\
\hline Kuwait & & MacKinnon approximate $p$-value $Z(t)=0.0075$ & $\mathrm{t}$-Statistics $\mathrm{p}$-value $=0.0594$ \\
\hline Turkey & \multirow{2}{*}{ D.InGCF } & MacKinnon approximate $p$-value $Z(t)=0.0000$ & $\mathrm{t}$-Statistics p-value $=0.0427$ \\
\hline Kuwait & & MacKinnon approximate $p$-value $Z(t)=0.0000$ & t-Statistics $p$-value $=0.0000$ \\
\hline Turkey & \multirow{2}{*}{ InENE } & MacKinnon approximate $p$-value $Z(t)=0.6564$ & t-Statistics $p$-value $=0.9877$ \\
\hline Kuwait & & MacKinnon approximate $p$-value $Z(t)=0.1502$ & t-Statistics $p$-value $=0.0279$ \\
\hline Turkey & \multirow{2}{*}{ D.InENE } & MacKinnon approximate $\mathrm{p}$-value $\mathrm{Z}(\mathrm{t})=0.0000$ & $\mathrm{t}$-Statistics p-value $=0.0000$ \\
\hline Kuwait & & MacKinnon approximate $\mathrm{p}$-value $\mathrm{Z}(\mathrm{t})=0.0000$ & $\mathrm{t}$-Statistics $\mathrm{p}$-value $=0.0000$ \\
\hline
\end{tabular}

Source: Computed by the Authors

findings of this test imply that the log levels were found to contain the unit root whereas the first difference was found to be stationary, assuming the same level of integration.

In this paper we also conduct a unit root test which allows for structural breaks (Perron unit root breakpoint test - Table 3) because a failure to do so creates the risk of falsely accepting the null hypothesis that a unit root exists when the data generating process is merely a trend-stationary process with a structural break. The Perron unit root breakpoint test justifies the evidence of the aforementioned unit root tests suggesting that the first differences are stationary. To proceed further with the empirical evidence, it was necessary to determine the optimal number of lags needed. In this regard, the procedure that relies on the information criteria was followed. These criteria indicate that the optimal number of lags for both countries was found to be seven (Table 6, Appendix 1).

Furthermore, we estimated the VAR models (Table 7, Appendix 1) and tested the stability of the models. All of the eigenvalues lie inside the unit circle; thereby, 
the VAR models satisfy the stability condition (Table 8 , Appendix 1). We have also investigated the serial correlation of the VAR model. Table 4 provides empirical evidence for both countries at the first and second levels. The null suggests no serial correlation. The $p$ values for both countries are higher than $5 \%$, indicating that the null hypothesis, suggesting no autocorrelation at the both lags (with a 5\% significance level), cannot be rejected.

Table 4. Testing for the serial correlation

\begin{tabular}{|c|c|c|}
\hline Country & lag & Prob>chi2 \\
\hline Turkey & 1 & 0.49597 \\
\hline \multirow{2}{*}{ Kuwait } & 2 & 0.84714 \\
\hline & 2 & 0.1274 \\
\hline
\end{tabular}

Source: Computed by the Authors

Table 5. Toda and Yamamoto Granger causality tests

\begin{tabular}{|c|c|c|c|}
\hline \multicolumn{2}{|c|}{ Variable } & Turkey & Kuwait \\
\hline Equation & Excluded & Prob>chi2 & Prob>chi2 \\
\hline CO & $\leftarrow$ GCF & 0.000 & 0.008 \\
\hline CO & $\leftarrow$ ENE & 0.000 & 0.000 \\
\hline GCF & $\leftarrow$ CO & 0.000 & 0.000 \\
\hline GCF & $\leftarrow$ ENE & 0.000 & 0.000 \\
\hline ENE & $\leftarrow$ CO & 0.000 & 0.000 \\
\hline ENE & $\leftarrow$ GCF & 0.000 & 0.000 \\
\hline
\end{tabular}

Source: Computed by the Authors

Finally, the presence of the causality relationship between $\mathrm{CO} 2$ emissions, gross capital formation and energy consumption in the case of the two countries of interest was examined. Table 5 provides the empirical evidence. Under the null hypothesis, there was no causal link between the analyzed variables; however, the alternative hypothesis suggests a potential causal link. The findings of the Toda and Yamamoto Granger causality tests were first presented in tabular form, and indicate a bidirectional link between all of the variables of interest. This holds true in the case of both Turkey and Kuwait. These findings are confirmed at the $1 \%$ significance level.
Figure 4. Causality direction (Turkey and Kuwait)

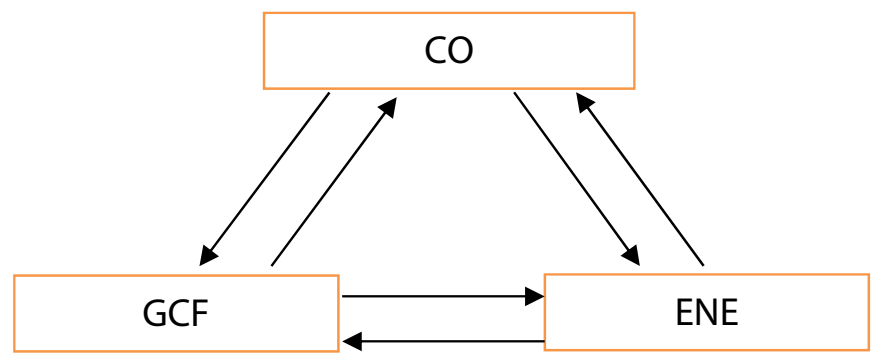

Note: Causality direction significant at $1 \%$.

Source: Computed by the Authors

Finally, the potential causal links (Figure 4) have been graphically presented. Based on this figure, gross capital formation tends to have a link with $\mathrm{CO} 2$ emissions, implying that gross capital formation is one of the key determinants of $\mathrm{CO} 2$ emissions, which is in line with Kivyiro and Arminen (2014), Abdouli and Hammami (2017) and Sapkota and Bastola (2017). Moreover, $\mathrm{CO} 2$ emissions are found to have an impact on gross capital formation, indicating the bidirectional link between these variables. Moreover, Figure 4 suggests a bidirectional link between energy consumption based on oil and $\mathrm{CO} 2$ emissions. Opposite to the link between $\mathrm{CO}$ and GCF, the link between $\mathrm{CO}$ and ENE has received considerable interest from the research community during the last decade. Most of the findings agree that energy based on fossil fuels tends to increase the $\mathrm{CO} 2$ emissions, leading to serious environmental issues.

\section{DISCUSSION AND CONCLUSION}

In this article, the relationship between $\mathrm{CO} 2$ emissions, gross capital formation and energy has been explored. Due to the fact that the bilateral relationship between Turkey and Kuwait has strengthened significantly in the previous years, this research analyzes the link of interest by comparing the cases of Turkey and Kuwait. The increased collaboration between these countries is linked to their joint interests. Thus, Turkey can meet their energy demands due to their ties with Kuwait, whereas Kuwait can attract investors from Turkey, especially in the economic sphere. It is also important to mention that these countries have deepened their relationship by signing many agreements regarding economic cooperation, defense and 
trade. Moreover, trade between Turkey and Kuwait is expected to increase to USD 3 billion annually by 2020 (https://www.kilinclaw.com.tr/turkey-and-kuwaits-close-relationship-will-boost-bilateral-trade/). Thereby, the researchers collected annual time-series data for these two countries for the period 1971-2014.

The empirical findings of this paper display a significant link between gross capital formation and $\mathrm{CO} 2$ emissions. This has identified inflow of investment as one of the most important determinants of CO2 emissions (Kivyiro and Arminen 2014; Abdouli and Hammami 2017; and Sapkota and Bastola 2017). In addition to these findings, $\mathrm{CO} 2$ emissions are also found to have a relationship with gross capital formation. The link running from $\mathrm{CO} 2$ emissions to gross capital formation advocates the existence of the pollution haven hypothesis, suggesting that countries with lower environmental protection standards tend to attract more investment, since firms from developed countries are likely to invest in these countries to reduce the costs connected with environmental protection (Chung 2014). Thus, these findings provide evidence of a bidirectional link between the variables of interest.

The study's findings also suggest a bidirectional causality between energy consumption and $\mathrm{CO} 2$ emissions (Gokmenoglu and Taspinar 2016). As indicated above, Turkey records a significant shortage in terms of energy and is thus a strongly energy-dependent country. In terms of Kuwait, fossil fuels have played a significant role in this economy which, as a consequence, has recorded impressive growth. This is expected, assuming that Kuwait has significant oil reserves. With regards to Turkey, the energy consumption tends to have a positive impact on $\mathrm{CO} 2$ emissions (Beser and Beser 2017). In addition to the exponential increase in macroeconomic performance, both countries have recorded a significant increase in their consumption of energy and $\mathrm{CO} 2$ emissions since the primary energy source is oil in both countries of interest (Al-Mulali and Che Sab 2018).

Finally, the empirical evidence suggests a bidirectional link between gross capital formation and energy consumption in the case of both Turkey and Kuwait. This finding implies that investment in Turkey is driven by economic growth, dependent on fossil fuels energy consumption. Thus, stable economic growth, driven by increased energy consumption, tends to create an attractive business environment for foreign investors. The bidirectional link between gross capital formation and energy consumption suggests that investment is an important driver of energy consumption (Mavikela and Khobai 2018). Thus, it is necessary to attract investments that are directed toward green energy production.

Based on the study's results, it is concluded that both gross capital formation and energy consumption play a significant role in $\mathrm{CO} 2$ emissions not only in Turkey but also in Kuwait. Rafindadi, Muye and Kaita (2018) indicated that investment itself reduces the depletion of the environment whereas the energy consumption arising from this capital tends to have a positive impact on $\mathrm{CO} 2$ emissions. Based on these findings, several policy implications are hereby presented. First, both countries need to promote clean energy which can ensure stricter environmental laws in each one. Moreover, higher income can stimulate society to demand more stringent laws that will protect the environment and force the multinational corporations to increase their energy efficiency and production and usage of green energy. Furthermore, the decision makers need to be aware of the pollution haven hypothesis while promoting the gross capital formation that will drive economic growth. For this purpose, it is key to apply regulations that will protect the environment and consequently avoid the negative externalities associated with the inflow of investment. In addition to these findings, it is important to emphasize that more stringent regulations will stimulate investors to promote technologies that will protect the environment and motivate local firms to conduct similar actions.

The governments of both countries should consider implementing more stringent environmental standards that will control carbon dioxide emissions. For this purpose, it is vital to direct investment toward research and development that will promote the development of environmentally-friendly technologies and consequently reduce the $\mathrm{CO} 2$ emissions. Moreover, both countries should take the necessary steps to switch from the use of fossil fuels to renewable energy that are, in general, both more affordable and cleaner. Due to the fact that global warming is a real global threat, a critical aim should be to reduce the $\mathrm{CO} 2$ emissions, which lead to the better environmental protection.

The limitations of this paper lie in the fact that only two countries were analyzed. Hence, to provide more informative evidence for policy makers at the global level, it is necessary to conduct similar studies that include more countries. Moreover, it will be interesting to include trade openness, taking into account the fact that Turkey and Kuwait both have very strong trade links. It would be useful to include other GCC countries and make comparisons with the case of Kuwait. In addition, the Turkish case ought to be compared with the OECD member states to provide more informative evidence about the link of interest. 


\section{REFERENCE LIST}

Abdouli, M., and Hammami, S. 2017. Investigating the causality links between environmental quality, foreign direct investment and economic growth in MENA countries. International Business Review 26(2): 264-278.

Abul, S., Satrovic, E., and Muslija, A. 2019. The link between energy consumption and economic growth in Gulf Cooperation Council countries. International Journal of Energy Economics and Policy 9(5): 38-45.

Ahmad, M., Zhao, Z. Y., Rehman, A., Shahzad, M., and Li, H. (2019). Revealing long- and short-run empirical interactions among foreign direct investment, renewable power generation, and $\mathrm{CO} 2$ emissions in China. Environmental Science and Pollution Research 26:22220-22245.

Akbulut Bekar, S. 2018. The relationship between $\mathrm{CO} 2$ emission and economic growth in Turkey: 1977-2014. International Journal of Economics and Administrative Studies, Prof. Dr. Harun Terzi Özel Sayısı: 193-206.

Alam, M. M., Md, W. M., Noman, A. H. M., and Ozturk, I. 2016. Relationships among carbon emissions, economic growth, energy consumption and population growth: testing environmental Kuznets curve hypothesis for Brazil, China, India and Indonesia. Ecol Indic. Elsevier Ltd. 70: 466-479.

Al-Mulali, U., and Che Sab, C. N. 2018. Energy consumption, $\mathrm{CO} 2$ emissions, and development in the UAE, Energy Sources. Part B: Economics, Planning, and Policy 13(4): 231-236.

Asif, M., Sharma, R., and Adow, A. 2015. An empirical investigation of the relationship between economic growth, urbanization, energy consumption, and emission in GCC countries: a panel data analysis. Asian Social Science 11(21): 270-284.

Aye, G.C., and Edoja, P.E. 2017. Effect of economic growth on $\mathrm{CO} 2$ emission in developing countries: Evidence from a dynamic panel threshold model. Cogent Econ.Financ. 90: 1-22.

Bashir, A., Thamrin, K.M.H., Farhan, M., Mukhlis, M., and Atiyatna, D.P. 2019. The causality between human capital, energy consumption, $\mathrm{CO} 2$ emissions, and economic growth: empirical evidence from Indonesia. International Journal of Energy Economics and Policy 9(2): 98-104.

Bekun, F. V., Emir, F., and Sarkodie, S. A. 2019. Another look at the relationship between energy consumption, carbon dioxide emissions, and economic growth in South Africa. Science of the Total Environment 655: 759-765.

Beser, M. K., and Beser, B. 2017. The relationship between energy consumption, CO2 emissions and GDP per capita: a revisit of the evidence from Turkey. The Journal of Operations Research, Statistics, Econometrics and Management Information Systems 5(3): 353-368.

Bozkurt, C., and Akan, Y. 2014. Economic growth, CO2 emissions and energy consumption: the Turkish case.
International Journal of Energy Economics and Policy 4(3): 484-494.

Bukhari, N., Shahzadi, K., and Shakil Ahmad, M. 2014. Consequence of FDI on $\mathrm{CO} 2$ emissions in case of Pakistan. Middle East Journal of Scientific Research 20(9): 1183-1189.

Cherniwchan, J. 2012. Economic growth, industrialization, and the environment. Resour. Energy Econ. 34: 442-467.

Chung, S. 2014. Environmental regulation and foreign direct investment: evidence from South Korea. Journal of Development Economics 108: 222-236.

Di Fonzo, M., Collen, B., and Mace, G. M. A. 2013. New method for identifying rapid decline dynamics in wild vertebrate populations. Ecol. Evol. 3: 2378-2391.

Dollar, D., Kleineberg, T., and Kraay, A. 2016. Growth still is good for the poor. Eur. Econ. Rev. 81: 68-85.

Gokmenoglu, K., Ozataca, N., and Eren, B. M. 2015. Relationship between industrial production, financial development and carbon emissions: the case of Turkey. Procedia Economics and Finance 25: 463-470.

Gokmenoglu, K., and Taspinar, N. 2016. The relationship between $\mathrm{CO} 2$ emissions, energy consumption, economic growth and FDI: the case of Turkey. The Journal of International Trade \& Economic Development 25(5): 706-723.

Halicioglu, F. 2009. An econometric study of CO2 emissions, energy consumption, income and foreign trade in Turkey. Energy Policy 37(3): 1156-1164.

Hamrita, M., and Mekdam, M. 2016. Energy consumption, emissions and economic growth nexus: Evidence from panel Granger causality test. Munich Personal RePEc Archive. https//mpra.ub.uni-muenchen.de/72908/ (accessed December 12, 2019).

Howarth, N., Galeotti, M., Lanza, A., and Dubey, K. 2017. Economic development and energy consumption in the GCC: an international sectoral analysis. Energy Transit. 1(6): 1-19.

Huesemann, M. H., and Huesemann, J. A. 2008. Will progress in science and technology avert or accelerate global collapse? A critical analysis and policy recommendations. Environ. Dev. Sustain. 10: 787-825.

Islam, M., Cheng, Y.,and Rajib, S.U. 2012. International trade and carbon emissions CO2: the case of Bangladesh. Journal of Economics and Sustainable Development 3(5): 18-26.

Kivyiro, P., and Arminen, H. 2014. Carbon dioxide emissions, energy consumption, economic growth, and foreign direct investment: causality analysis for sub-Saharan Africa. Energy 74(C): 595-606.

Korhan, K., and Sadeghieh, M. 2019. Financial development, $\mathrm{CO}_{2}$ emissions, fossil fuel consumption and economic growth: the case of Turkey. Strategic Planning for Energy and the Environment 38(4): 7-28. 
Kuznets, S. 1955. Economic growth and income inequality. American Economic Review 45: 1-28.

Lu, W.2017. Greenhouse gas emissions, energy consumption and economic growth: a panel cointegration analysis for 16 Asian countries. Int. J. Environ. Res. Public Heal. 14: 14-36.

Magazzino, C. 2016. The relationship between real GDP, CO2 emissions, and energy use in the GCC countries: A time series approach. Cogent Economic and Finance 4: 1-20.

Mavikela, N., and Khobai, H. 2018. Investigating the link between foreign direct investment, energy consumption and economic growth in Argentina. MPRA Paper No. 83960. https://mpra.ub.uni-muenchen.de/83960/ (accessed January 27, 2020).

Osman, M., Gachino, G., and Hoque, A. 2016. Electricity consumption and economic growth in the GCC countries: panel data analysis. Energy Policy 98: 318-327.

Oyedokun, G. 2019. Human capital formation and economic growth in Nigeria. International Journal of Finance \& Banking Studies 7(3): 44-65.

Ozturk, Z., and Oz, D. 2016. The relationship between energy consumption, income, foreign direct investment, and $\mathrm{CO} 2$ emissions: the case of Turkey. Çankırı Karatekin Üniversitesi IiBF Dergisi 6(2): 269-288.

Phillips, P.C.B., and Perron, P. 1988. Testing for unit roots in time series regression. Biometrika 75: 335-346.

Polat, M.A., and Ergun, S. 2018. The relationship between economic growth, $\mathrm{CO} 2$ emissions and health expenditures in Turkey under structural breaks. Business and Economics Research Journal 9(3): 481-497.

Rafindadi, A. A., Muye, I. M., and Kaita, R. A. 2018. The effects of FDI and energy consumption on environmental pollution in predominantly resource-based economies of the GCC. Sustainable Energy Technologies and Assessments 25: 126-137.

Rahman, Z. U., and Ahmad, M. 2019. Modeling the relationship between gross capital formation and $\mathrm{CO} 2$ (a) symmetrically in the case of Pakistan: an empirical analysis through NARDL approach. Environmental Science and Pollution Research 26(8): 8111-8124.

Saatci, M., and Durmul, Y. 2013. The relationship between energy consumption and economic growth: evidence from a structural break analysis for Turkey. International Journal of Energy Economics and Policy 3(1): 20-29.

Said, S.E., and Dickey, D. 1984. Testing for unit roots in autoregressive moving-average models with unknown order. Biometrika 71: 599-607.

Salahuddin, M., Gow, J., and Ozturk, I. 2015. Is the long-run relationship between economic growth, electricity consumption, carbon dioxide emissions and financial development in Gulf Cooperation Council Countries robust? Renewable and Sustainable Energy Reviews 51: 317-326.

Sapkota, P., and Bastola, U. 2017. Foreign direct investment, income, and environmental pollution in developing countries: panel data analysis of Latin America. Energy Econ Elsevier BV. 64: 206-212.

Satrovic, E. 2019. Emerging trends in trade in Turkey. Munich: GRIN Verlag.

Sweidan, O.D., and Alwaked, A.A. 2016. Economic development and the energy intensity of human well-being: evidence from the GCC countries 55: 1363-1369.

Thaker, M.A.M, Thaker, H.M, Amin, F.A., and Ptichay, A.A. 2019. Electricity consumption and economic growth; a revisit study of their causality in Malaysia. Etikonomi; Jornal Ekonomi 18(1): 1-12.

Toda, H. Y., and Yamamoto, T. 1995. Statistical inference in vector autoregressions with possibly integrated processes. Journal of Econometrics 66(1-2): 225-250.

Yildirim, H. H., and Sakarya, S. 2016. Economic growth and CO2 emissions in Turkey. Paper presented at the $8^{\text {th }}$ International Ege Energy Symposium, Afyonkarahisar, Turkey, May. 
APPENDIX 1

Table 6. Optimal number of lags

\begin{tabular}{|c|c|c|c|c|c|c|c|c|c|}
\hline Country & lag & LL & LR & df & $\mathrm{p}$ & FPE & $\mathrm{AIC}$ & $\mathrm{HQIC}$ & SBIC \\
\hline \multirow{8}{*}{ Turkey } & 0 & -14.964 & & & & 0.001 & 0.971 & 1.017 & 1.102 \\
\hline & 1 & 60.961 & 151.850 & 9 & 0.000 & 0.000 & -2.647 & -2.462 & $-2.124^{*}$ \\
\hline & 2 & 70.167 & 18.413 & 9 & 0.031 & 0.000 & -2.658 & -2.335 & -1.743 \\
\hline & 3 & 75.926 & 11.518 & 9 & 0.242 & 0.000 & -2.483 & -2.022 & -1.176 \\
\hline & 4 & 94.045 & 36.238 & 9 & 0.000 & 0.000 & -2.975 & -2.377 & -1.277 \\
\hline & 5 & 101.336 & 14.582 & 9 & 0.103 & 0.000 & -2.883 & -2.146 & -0.793 \\
\hline & 6 & 107.667 & 12.662 & 9 & 0.179 & 0.000 & -2.739 & -1.864 & -0.257 \\
\hline & 7 & 131.431 & $47.529^{*}$ & 9 & 0.000 & $0.000^{*}$ & $-3.537^{*}$ & $-2.523^{*}$ & -0.663 \\
\hline \multirow{8}{*}{ Kuwait } & 0 & -10.108 & & & & 0.000 & 0.709 & 0.755 & 0.839 \\
\hline & 1 & 8.361 & 36.937 & 9 & 0.000 & 0.000 & 0.197 & 0.381 & 0.719 \\
\hline & 2 & 37.273 & 57.825 & 9 & 0.000 & 0.000 & -0.880 & -0.189 & $0.035^{*}$ \\
\hline & 3 & 44.962 & 15.377 & 9 & 0.081 & 0.000 & -0.809 & -0.348 & 0.497 \\
\hline & 4 & 57.829 & 25.734 & 9 & 0.002 & $0.000^{*}$ & -1.018 & -0.419 & 0.680 \\
\hline & 5 & 62.902 & 10.146 & 9 & 0.339 & 0.000 & -0.806 & -0.069 & 1.284 \\
\hline & 6 & 71.951 & 18.097 & 9 & 0.034 & 0.000 & -0.808 & 0.067 & 1.674 \\
\hline & 7 & 89.605 & $35.309 *$ & 9 & 0.000 & 0.000 & $-1.276^{*}$ & $-0.617^{*}$ & 1.619 \\
\hline
\end{tabular}

Source: Computed by the Authors 
Table 7. The Vector autoregression models

\begin{tabular}{|c|c|c|c|c|c|c|c|c|c|c|c|c|}
\hline \multirow{2}{*}{$\begin{array}{l}\text { Country } \\
\text { Equation }\end{array}$} & \multicolumn{6}{|c|}{ Turkey } & \multicolumn{6}{|c|}{ Kuwait } \\
\hline & Parms & \multicolumn{2}{|c|}{ RMSE } & R-sq & chi2 & P>chi2 & Parms & \multicolumn{2}{|c|}{ RMSE } & R-sq & chi2 & $\mathrm{P}>\mathrm{chi} 2$ \\
\hline $\ln C O$ & 22.000 & \multicolumn{2}{|c|}{0.056} & 0.984 & 2305.441 & 0.000 & 22.000 & \multicolumn{2}{|c|}{0.190} & 0.907 & 360.143 & 0.000 \\
\hline $\operatorname{lnGCF}$ & 22.000 & 0.1 & 30 & .844 & 199.563 & 0.000 & 22.000 & 0.1 & & 352 & 213.524 & 0.000 \\
\hline InENE & 22.000 & 0.0 & 49 & .984 & 2273.599 & 0.000 & 22.000 & 0.2 & & 389 & 295.091 & 0.000 \\
\hline Var. & Coef. & St. Er. & $z$ & $P>z$ & $\begin{array}{r}{[95 \%} \\
\text { Inte }\end{array}$ & & Coef. & St. Er. & $z$ & $P>z$ & $\begin{array}{r}{[95 \%} \\
\text { Inte }\end{array}$ & $\begin{array}{l}\text { Conf. } \\
\text { erval] }\end{array}$ \\
\hline InCO & & & & key & & & & & $\mathrm{Ku}$ & ait & & \\
\hline $\ln C O$ & & & & & & & & & & & & \\
\hline L1. & 0.939 & 0.415 & 2.260 & 0.024 & 0.125 & 0.939 & -0.349 & 0.158 & -2.210 & 0.027 & -0.659 & -0.040 \\
\hline L2. & 0.098 & 0.394 & 0.250 & 0.804 & -0.675 & 0.098 & 0.784 & 0.205 & 3.810 & 0.000 & 0.381 & 1.186 \\
\hline L3. & 0.169 & 0.380 & 0.440 & 0.657 & -0.575 & 0.169 & 0.172 & 0.234 & 0.730 & 0.463 & -0.287 & 0.630 \\
\hline L4. & 0.355 & 0.360 & 0.990 & 0.325 & -0.351 & 0.355 & 0.414 & 0.242 & 1.710 & 0.087 & -0.060 & 0.888 \\
\hline L5. & -0.131 & 0.393 & -0.330 & 0.739 & -0.902 & -0.131 & 0.129 & 0.247 & 0.520 & 0.601 & -0.354 & 0.613 \\
\hline L6. & 0.210 & 0.375 & 0.560 & 0.575 & -0.524 & 0.210 & 0.576 & 0.232 & 2.490 & 0.013 & 0.122 & 1.030 \\
\hline L7. & -0.479 & 0.355 & -1.350 & 0.177 & -1.174 & -0.479 & -0.285 & 0.237 & -1.200 & 0.229 & -0.749 & 0.179 \\
\hline $\ln G C F$ & & & & & & & & & & & & \\
\hline L1. & -0.015 & 0.087 & -0.180 & 0.860 & -0.187 & -0.015 & 0.111 & 0.193 & 0.570 & 0.567 & -0.268 & 0.490 \\
\hline L2. & 0.081 & 0.101 & 0.800 & 0.426 & -0.118 & 0.081 & 0.145 & 0.207 & 0.700 & 0.482 & -0.260 & 0.550 \\
\hline L3. & 0.008 & 0.105 & 0.080 & 0.939 & -0.198 & 0.008 & 0.201 & 0.218 & 0.920 & 0.357 & -0.227 & 0.629 \\
\hline L4. & -0.165 & 0.109 & -1.510 & 0.130 & -0.379 & -0.165 & 0.224 & 0.188 & 1.200 & 0.232 & -0.144 & 0.592 \\
\hline L5. & 0.106 & 0.105 & 1.010 & 0.312 & -0.099 & 0.106 & -0.057 & 0.162 & -0.350 & 0.727 & -0.373 & 0.260 \\
\hline L6. & -0.025 & 0.113 & -0.220 & 0.823 & -0.247 & -0.025 & 0.203 & 0.146 & 1.390 & 0.165 & -0.083 & 0.489 \\
\hline L7. & 0.372 & 0.071 & 5.280 & 0.000 & 0.234 & 0.372 & 0.433 & 0.124 & 3.480 & 0.001 & 0.189 & 0.677 \\
\hline InENE & & & & & & & & & & & & \\
\hline L1. & -0.154 & 0.521 & -0.300 & 0.768 & -1.176 & -0.154 & 0.800 & 0.131 & 6.130 & 0.000 & 0.544 & 1.056 \\
\hline L2. & -0.243 & 0.521 & -0.470 & 0.642 & -1.264 & -0.243 & -0.828 & 0.225 & -3.680 & 0.000 & -1.269 & -0.387 \\
\hline L3. & -0.275 & 0.535 & -0.510 & 0.607 & -1.324 & -0.275 & 0.278 & 0.256 & 1.090 & 0.277 & -0.223 & 0.780 \\
\hline L4. & 0.081 & 0.510 & 0.160 & 0.874 & -0.918 & 0.081 & -0.761 & 0.277 & -2.750 & 0.006 & -1.303 & -0.218 \\
\hline L5. & -0.264 & 0.511 & -0.520 & 0.605 & -1.265 & -0.264 & 0.111 & 0.295 & 0.380 & 0.707 & -0.467 & 0.689 \\
\hline L6. & -0.340 & 0.492 & -0.690 & 0.489 & -1.303 & -0.340 & -0.597 & 0.252 & -2.370 & 0.018 & -1.091 & -0.102 \\
\hline L7. & 1.067 & 0.439 & 2.430 & 0.015 & 0.207 & 1.067 & 0.509 & 0.210 & 2.420 & 0.015 & 0.097 & 0.921 \\
\hline _cons & 1.018 & 2.620 & 0.390 & 0.698 & -4.117 & 1.018 & 1.900 & 1.220 & 1.560 & 0.119 & -0.491 & 4.291 \\
\hline $\ln G C F$ & & & & & & & & & & & & \\
\hline InCO & & & & & & & & & & & & \\
\hline L1. & 0.653 & 0.955 & 0.680 & 0.494 & -1.218 & 0.653 & 0.888 & 0.120 & 7.410 & 0.000 & 0.653 & 1.123 \\
\hline L2. & 0.536 & 0.907 & 0.590 & 0.554 & -1.241 & 0.536 & 0.093 & 0.156 & 0.600 & 0.551 & -0.213 & 0.399 \\
\hline L3. & 0.707 & 0.873 & 0.810 & 0.418 & -1.003 & 0.707 & -0.691 & 0.178 & -3.890 & 0.000 & -1.039 & -0.343 \\
\hline L4. & 0.939 & 0.828 & 1.130 & 0.257 & -0.685 & 0.939 & -0.338 & 0.184 & -1.840 & 0.066 & -0.697 & 0.022 \\
\hline L5. & -0.166 & 0.904 & -0.180 & 0.854 & -1.938 & -0.166 & -0.425 & 0.187 & -2.270 & 0.023 & -0.793 & -0.058 \\
\hline L6. & 0.988 & 0.861 & 1.150 & 0.251 & -0.700 & 0.988 & -0.257 & 0.176 & -1.460 & 0.143 & -0.602 & 0.087 \\
\hline L7. & -2.556 & 0.816 & -3.130 & 0.002 & -4.156 & -2.556 & -0.589 & 0.180 & -3.280 & 0.001 & -0.942 & -0.237 \\
\hline
\end{tabular}


Table 7. Cntd.

\begin{tabular}{|c|c|c|c|c|c|c|c|c|c|c|c|c|}
\hline \multicolumn{13}{|l|}{$\ln G C F$} \\
\hline L1. & 0.432 & 0.201 & 2.150 & 0.032 & 0.038 & 0.432 & 0.353 & 0.147 & 2.400 & 0.016 & 0.065 & 0.641 \\
\hline L2. & -0.102 & 0.233 & -0.440 & 0.662 & -0.558 & -0.102 & -0.593 & 0.157 & -3.780 & 0.000 & -0.900 & -0.285 \\
\hline L3. & 0.128 & 0.242 & 0.530 & 0.597 & -0.346 & 0.128 & -0.257 & 0.166 & -1.550 & 0.121 & -0.582 & 0.068 \\
\hline L4. & -0.516 & 0.251 & -2.060 & 0.040 & -1.008 & -0.516 & -0.534 & 0.143 & -3.750 & 0.000 & -0.813 & -0.254 \\
\hline L5. & 0.371 & 0.241 & 1.540 & 0.123 & -0.100 & 0.371 & -0.083 & 0.123 & -0.680 & 0.498 & -0.324 & 0.157 \\
\hline L6. & -0.005 & 0.260 & -0.020 & 0.985 & -0.515 & -0.005 & -0.148 & 0.111 & -1.340 & 0.182 & -0.365 & 0.069 \\
\hline L7. & -0.088 & 0.222 & -0.400 & 0.691 & -0.524 & -0.088 & -0.154 & 0.101 & -1.530 & 0.125 & -0.351 & 0.043 \\
\hline \multicolumn{13}{|l|}{ InENE } \\
\hline L1. & -0.654 & 1.199 & -0.550 & 0.585 & -3.003 & -0.654 & -0.118 & 0.099 & -1.190 & 0.234 & -0.312 & 0.076 \\
\hline L2. & -0.348 & 1.198 & -0.290 & 0.772 & -2.695 & -0.348 & -0.380 & 0.171 & -2.220 & 0.026 & -0.715 & -0.045 \\
\hline L3. & -1.228 & 1.230 & -1.000 & 0.318 & -3.639 & -1.228 & 0.634 & 0.194 & 3.270 & 0.001 & 0.254 & 1.015 \\
\hline L4. & 0.327 & 1.172 & 0.280 & 0.780 & -1.970 & 0.327 & -0.049 & 0.210 & -0.230 & 0.816 & -0.461 & 0.363 \\
\hline L5. & -1.397 & 1.174 & -1.190 & 0.234 & -3.699 & -1.397 & 0.619 & 0.224 & 2.760 & 0.006 & 0.180 & 1.058 \\
\hline L6. & -0.605 & 1.130 & -0.530 & 0.593 & -2.820 & -0.605 & 0.265 & 0.191 & 1.380 & 0.167 & -0.111 & 0.640 \\
\hline L7. & 3.206 & 1.009 & 3.180 & 0.001 & 1.227 & 3.206 & 0.372 & 0.181 & 2.050 & 0.040 & 0.017 & 0.728 \\
\hline _cons & 6.168 & 6.025 & 1.020 & 0.306 & -5.641 & 6.168 & -1.199 & 0.926 & -1.290 & 0.196 & -3.014 & 0.617 \\
\hline \multicolumn{13}{|l|}{ InENE } \\
\hline \multicolumn{13}{|l|}{$\ln C O$} \\
\hline L1. & 0.690 & 0.364 & 1.900 & 0.058 & -0.023 & 0.690 & -0.942 & 0.179 & -5.250 & 0.000 & -1.293 & -0.590 \\
\hline L2. & -0.284 & 0.346 & -0.820 & 0.411 & -0.961 & -0.284 & 0.598 & 0.233 & 2.560 & 0.010 & 0.140 & 1.055 \\
\hline L3. & 0.101 & 0.333 & 0.300 & 0.761 & -0.551 & 0.101 & 0.064 & 0.266 & 0.240 & 0.811 & -0.457 & 0.584 \\
\hline L4. & 0.185 & 0.316 & 0.580 & 0.559 & -0.434 & 0.185 & 0.626 & 0.275 & 2.280 & 0.023 & 0.088 & 1.164 \\
\hline L5. & -0.314 & 0.345 & -0.910 & 0.362 & -0.989 & -0.314 & 0.521 & 0.280 & 1.860 & 0.063 & -0.028 & 1.070 \\
\hline L6. & 0.123 & 0.328 & 0.370 & 0.709 & -0.521 & 0.123 & 0.171 & 0.263 & 0.650 & 0.516 & -0.345 & 0.686 \\
\hline L7. & 0.262 & 0.110 & 2.390 & 0.017 & 0.048 & 0.262 & 0.577 & 0.269 & 2.150 & 0.032 & 0.050 & 1.104 \\
\hline \multicolumn{13}{|l|}{$\ln G C F$} \\
\hline L1. & -0.033 & 0.077 & -0.430 & 0.669 & -0.183 & -0.033 & 0.717 & 0.220 & 3.260 & 0.001 & 0.286 & 1.147 \\
\hline L2. & 0.082 & 0.089 & 0.920 & 0.355 & -0.092 & 0.082 & 0.455 & 0.235 & 1.940 & 0.053 & -0.005 & 0.915 \\
\hline L3. & -0.013 & 0.092 & -0.140 & 0.888 & -0.194 & -0.013 & 0.280 & 0.248 & 1.130 & 0.259 & -0.206 & 0.766 \\
\hline L4. & -0.071 & 0.096 & -0.740 & 0.458 & -0.258 & -0.071 & 0.581 & 0.213 & 2.720 & 0.006 & 0.163 & 0.998 \\
\hline L5. & 0.023 & 0.092 & 0.250 & 0.802 & -0.157 & 0.023 & 0.163 & 0.183 & 0.890 & 0.375 & -0.197 & 0.522 \\
\hline L6. & 0.008 & 0.099 & 0.080 & 0.935 & -0.186 & 0.008 & 0.447 & 0.166 & 2.700 & 0.007 & 0.122 & 0.772 \\
\hline L7. & 0.386 & 0.050 & 7.740 & 0.000 & 0.288 & 0.386 & -0.307 & 0.150 & -2.040 & 0.041 & -0.601 & -0.012 \\
\hline \multicolumn{13}{|l|}{ InENE } \\
\hline L1. & 0.153 & 0.457 & 0.330 & 0.738 & -0.743 & 0.153 & 1.173 & 0.148 & 7.910 & 0.000 & 0.883 & 1.464 \\
\hline L2. & 0.073 & 0.457 & 0.160 & 0.873 & -0.822 & 0.073 & -0.378 & 0.255 & -1.480 & 0.139 & -0.878 & 0.123 \\
\hline L3. & 0.018 & 0.469 & 0.040 & 0.970 & -0.901 & 0.018 & 0.066 & 0.291 & 0.230 & 0.820 & -0.503 & 0.635 \\
\hline L4. & -0.014 & 0.447 & -0.030 & 0.976 & -0.889 & -0.014 & -0.371 & 0.314 & -1.180 & 0.238 & -0.988 & 0.245 \\
\hline L5. & 0.176 & 0.448 & 0.390 & 0.693 & -0.701 & 0.176 & -0.851 & 0.335 & -2.540 & 0.011 & -1.507 & -0.194 \\
\hline L6. & -0.260 & 0.431 & -0.600 & 0.546 & -1.105 & -0.260 & 0.307 & 0.286 & 1.070 & 0.284 & -0.255 & 0.868 \\
\hline L7. & 0.680 & 0.385 & 1.770 & 0.077 & -0.074 & 0.680 & -0.706 & 0.271 & -2.600 & 0.009 & -1.237 & -0.174 \\
\hline _cons & 1.012 & 2.297 & 0.440 & 0.659 & -3.489 & 1.012 & 4.243 & 1.385 & 3.060 & 0.002 & 1.527 & 6.958 \\
\hline
\end{tabular}

Source: Computed by the Authors 
Table 8. Stability of the models

\begin{tabular}{|c|c|c|c|c|c|c|c|}
\hline \multicolumn{4}{|c|}{ Turkey } & \multicolumn{4}{|c|}{ Kuwait } \\
\hline \multicolumn{3}{|c|}{ Eigenvalue } & \multirow{2}{*}{$\begin{array}{l}\text { Modulus } \\
0.995584\end{array}$} & \multicolumn{3}{|c|}{ Eigenvalue } & \multirow{2}{*}{$\begin{array}{l}\text { Modulus } \\
0.932231\end{array}$} \\
\hline 0.9955838 & & & & -0.38641 & + & $.8483755 i$ & \\
\hline-0.6504167 & + & $.7299475 i$ & 0.977684 & -0.38641 & - & $.8483755 i$ & 0.932231 \\
\hline-0.6504167 & - & $.7299475 i$ & 0.977684 & 0.922603 & & & 0.922603 \\
\hline 0.9469386 & & & 0.946939 & 0.247365 & + & $.8670634 \mathrm{i}$ & 0.901659 \\
\hline 0.3119662 & + & $.882062 \mathrm{i}$ & 0.935605 & 0.247365 & - & $.8670634 i$ & 0.901659 \\
\hline 0.3119662 & - & $.882062 \mathrm{i}$ & 0.935605 & -0.72847 & + & $.5288965 i$ & 0.900226 \\
\hline 0.8799019 & + & $.2814235 i$ & 0.923811 & -0.72847 & - & $.5288965 i$ & 0.900226 \\
\hline 0.8799019 & - & $.2814235 i$ & 0.923811 & -0.52418 & + & $.7246146 \mathrm{i}$ & 0.894336 \\
\hline 0.5680597 & + & $.696142 i$ & 0.898502 & -0.52418 & - & $.7246146 i$ & 0.894336 \\
\hline 0.5680597 & - & $.696142 \mathrm{i}$ & 0.898502 & 0.863385 & + & $.2045224 i$ & 0.887278 \\
\hline-0.0175377 & + & $.8710275 i$ & 0.871204 & 0.863385 & - & $.2045224 i$ & 0.887278 \\
\hline-0.0175377 & - & $.8710275 i$ & 0.871204 & 0.450488 & + & $.7519798 \mathrm{i}$ & 0.876592 \\
\hline 0.6931191 & + & $.5262527 i$ & 0.870262 & 0.450488 & - & $.7519798 \mathrm{i}$ & 0.876592 \\
\hline 0.6931191 & - & $.5262527 i$ & 0.870262 & -0.85596 & + & $.1848759 i$ & 0.875698 \\
\hline-0.6778359 & + & $.5278408 i$ & 0.859114 & -0.85596 & - & $.1848759 i$ & 0.875698 \\
\hline-0.6778359 & - & $.5278408 \mathrm{i}$ & 0.859114 & 0.537957 & + & $.6100545 i$ & 0.813366 \\
\hline-0.789439 & + & $.2391249 i$ & 0.82486 & 0.537957 & - & $.6100545 i$ & 0.813366 \\
\hline-0.789439 & - & $.2391249 i$ & 0.82486 & 0.673428 & + & $.3917871 \mathrm{i}$ & 0.779104 \\
\hline-0.1781513 & + & $.7966297 i$ & 0.816307 & 0.673428 & - & $.3917871 \mathrm{i}$ & 0.779104 \\
\hline-0.1781513 & - & $.7966297 i$ & 0.816307 & -0.15034 & + & $.7479661 \mathrm{i}$ & 0.762925 \\
\hline-0.6986828 & & & 0.698683 & -0.15034 & - & $.7479661 \mathrm{i}$ & 0.762925 \\
\hline
\end{tabular}

Source: Computed by the Authors 